\title{
Supplementary material to "The sulfur- and halogen-rich super eruption Los Chocoyos and its impacts on climate and environment"
}

Hans Brenna ${ }^{1}$, Steffen Kutterolf ${ }^{2}$, Michael J. Mills ${ }^{3}$, Kirstin Krüger ${ }^{1}$

${ }^{1}$ Section for Meteorology and Oceanography, Department of Geosciences, University of Oslo, P.O. Box 1022 Blindern,0315, Oslo, Norway.

${ }^{2}$ GEOMAR | Helmholtz Centre for Ocean Research Kiel, Wischhofstrasse 1-3, 24148, Kiel, Germany

${ }^{3}$ Atmospheric Chemistry Observations \& Modeling Laboratory, National Center for Atmospheric Research, P.O. Box 3000, Boulder, Colorado 80307-3000, USA

Correspondence: Kirstin Krüger (kkrueger@geo.uio.no) 


\section{Supplementary figures}
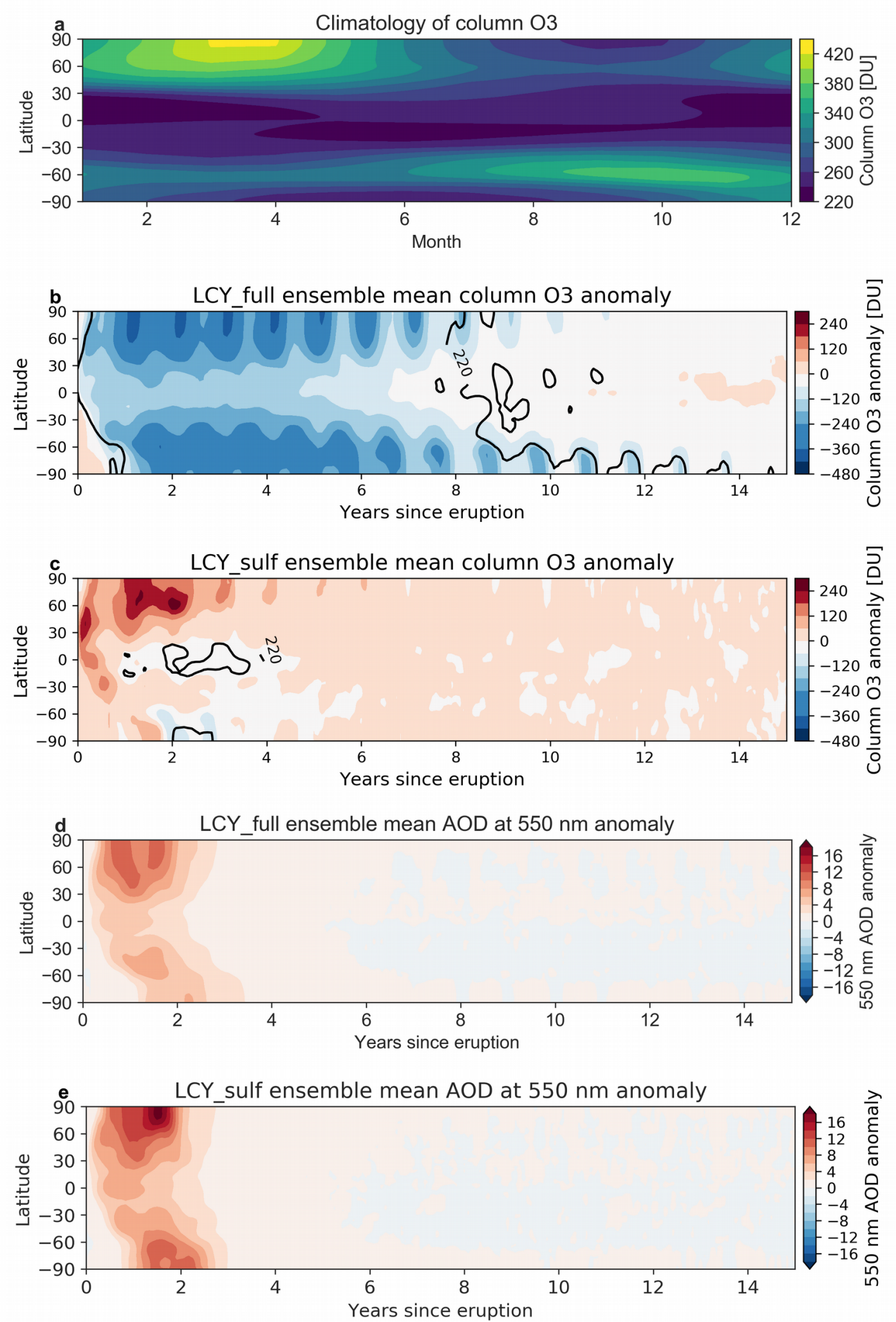

Figure S1: Zonal mean ozone and AOD evolution after the Los Chocoyos eruption. (a) Column ozone climatology for the CTR. (b) LCY_full ensemble mean column ozone anomaly. (c) LCY_sulf ensemble mean column ozone anomaly. (d) LCY_full ensemble mean AOD anomaly. (e) LCY_sulf ensemble mean AOD anomaly 

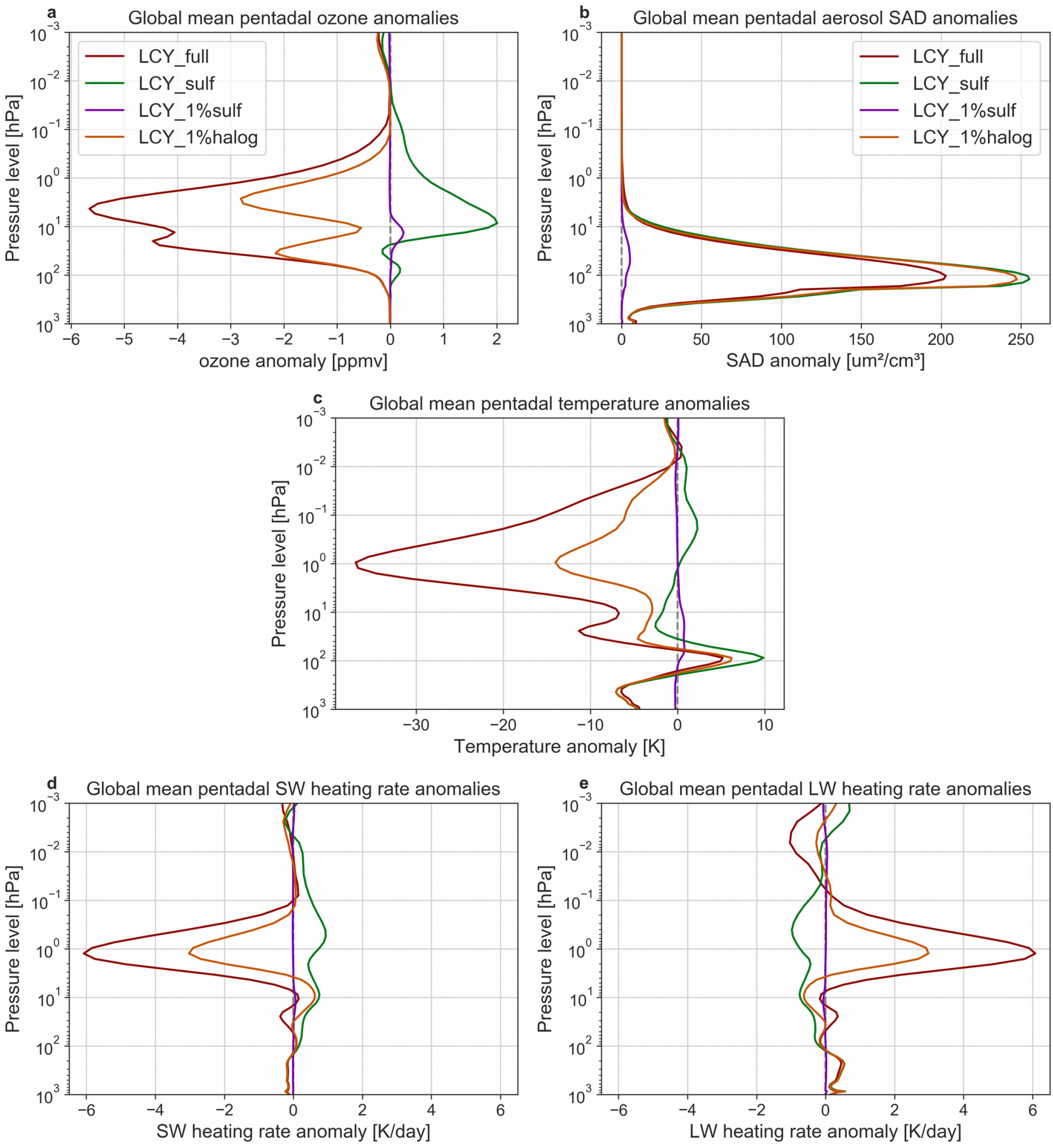

Figure S2: Global mean pentadal anomaly profiles of (a) ozone, (b) aerosol surface area density (SAD), (c) temperature, (d) short wave heating rate and (d) long wave heating rate of the LCY eruption scenarios. 

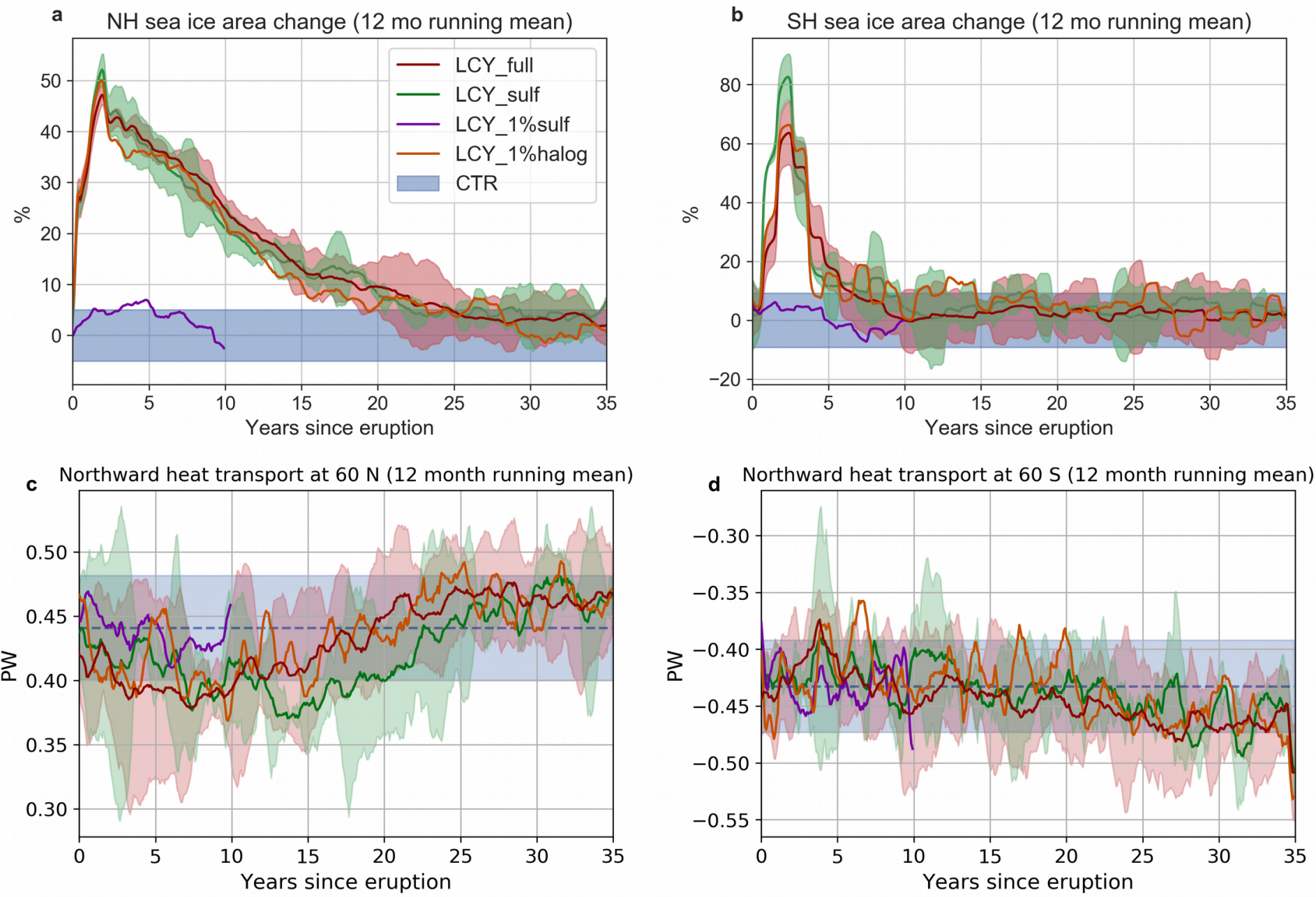

Figure S3: Hemispheric mean sea ice changes and. (a) NH, (b) SH. Northward ocean heat transport at (c) $60^{\circ} \mathrm{N}$, and (d) $60^{\circ} \mathrm{S}$ for CTR, LCY_full and LCY_sulf ensembles. 

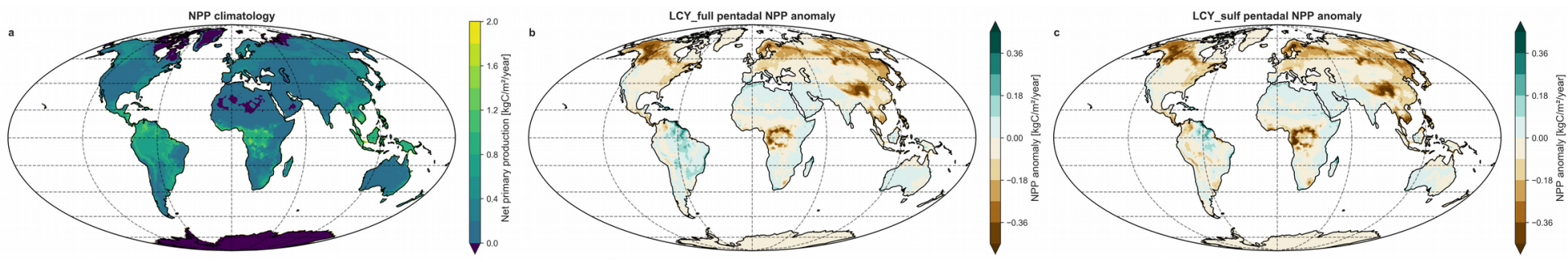

Figure S4: Global maps of net primary productivity (NPP) climatology for CTR (a) and posteruption pentadal anomalies for LCY_full (b) and LCY_sulf (c) ensembles. White areas on the map indicates invalid values. 